\title{
MANIPULAÇÕES NO CIBERESPAÇO: DISCURSO E LINGUAGEM DO TURISMO PANTANEIRO
}

\author{
Renan Ramires de Azevedo ${ }^{1}$ \\ Maria Luceli Faria Batistote ${ }^{2}$
}

\begin{abstract}
Resumo
A presente pesquisa, de caráter qualitativo-interpretativista, busca analisar o funcionamento discursivo sobre a temática "turismo" na mídia, com o intuito de compreender como se dá a persuasão do sujeito, de modo a convencê-lo a adquirir determinado produto ou serviço ou, ainda, aceitar uma ideia como verdadeira. Dessa forma, selecionou-se a reportagem intitulada "Bonito: o paraíso brasileiro de ecoturismo no MS", que por ventura está presente em dois sites da internet, de maneiras distintas, circunstanciando assim na análise, a comparação dos efeitos de sentido e sua eficiência no processo de condução do leitor. O embasamento teórico da pesquisa advém da Semiótica Greimasiana, por meio dos preceitos de Barros (1990) e Fiorin (2011), no que concerne à análise do funcionamento do plano do conteúdo, e à semiótica visual, desdobramento da francesa, com os estudos de Pietroforte (2007), norteando o desenvolvimento da análise no plano da expressão.
\end{abstract}

Palavras-chave: Semiótica Greimasiana. Turismo. Paraíso brasileiro.

\section{MANIPULATIONS IN CYBERSPACE: DISCOURSE AND LANGUAGE OF PANTANAL TOURISM}

\begin{abstract}
This qualitative-interpretative research aims to analyze the discursive functioning on the theme "tourism" in the media, in order to understand how the subject persuasion, in order to convince him to acquire a particular product or service or accept an idea as true. Thus, we selected the article entitled "Bonito: The Brazilian Paradise of Ecotourism in MS", which is perhaps present in two websites, in different ways, thus enabling the analysis, the comparison of the effects of meaning and their effectiveness in the process of driving the reader. The theoretical basis of the research comes from the Greimasian Semiotics, through the precepts of Diana Luz Pessoa de Barros (1990) and José Luiz Fiorin (2011), regarding the analysis of the functioning of the content plane, and the visual semiotics, unfolding French, with the studies of Antonio Vicente Seraphim Pietroforte (2007), guiding the development of analysis in the plane of expression.
\end{abstract} Keywords: Greimasian Semiotics. Tourism. Brazilian Paradise.

\section{INTRODUÇÃO}

Para o marketing de lugares e serviços no turismo pode-se dizer que não importa tanto qual imagem irá representar um produto, mas o que importa é que ela seja atrativa. (SÁ, 2002, p. 13)

\footnotetext{
${ }^{1}$ Graduando em Letras com Habilitação em Português/Espanhol, pela Faculdade de Artes, Letras e Comunicação (FAALC - UFMS). ORCID <http://orcid.org/0000-0002-3297-3021>. E-mail: renan_ramires@outlook.com.

2 Doutora em Linguística e Professora da Pós-Graduação Mestrado e Doutorado em Estudos de Linguagens FAALC/UFMS. ORCID < https://orcid.org/0000-0003-0023-1186>. E-mail: marialucelifaria@gmail.com.
} 


\section{Linguagens - Revista de Letras, Artes e Comunicação - ISSN 1981- 9943 \\ Blumenau, v. 14, n. 2, p. 114-127, maio/ago. 2020. \\ DOI: http://dx.doi.org/10.7867/1981-9943.2020v14n2p114-127}

O turismo contemporâneo, fruto da globalização, apresenta característica da modernidade tardia (GIDDENS; PIERSON, 2000). De acordo com a Organização Mundial do Turismo - OMT (1997, p. 18), o conceito de turismo revela ser "as atividades das pessoas que viajam e permanecem fora de seu ambiente habitual por não mais de um ano consecutivo, para lazer, negócios ou outros objetivos". Em outras palavras, o turismo é uma prática humana que se refere a sair de sua localidade de rotina por motivações como trabalho ou até mesmo para, simplesmente, conhecer distintas culturas e geografias.

Como tudo que é de interesse humano, o turismo enquanto produto também se utiliza de marketing, ou seja, está ligado à materiais de divulgação ou processos utilizados para aproximar compradores e vendedores (OMT, 1997, p. 112), pois, sendo bem sucedida, tal ligação entre cliente e produto ocasiona visitas na localidade em questão refletindo lucro para os compatriotas bem como para economia local.

Com o crescimento acelerado da tecnologia torna-se difícil designar, classificar e/ou acompanhar suas variações técnicas e, sobretudo, pontuar qual a linguagem que será a ela anexada pelos usuários, sobremaneira aqueles que se vinculam à internet. O ciberespaço, como é nomeado esse novo campo de interação, é o local virtual onde acontecem múltiplas atividades, este é considerado o mais novo local de "disponibilização" de informações, possibilitado pelas novas tecnologias. O ciberespaço pode ser concebido como um novo mundo, um novo espaço de significações, um novo meio de interação, comunicação e de vida em sociedade. Esse universo não é irreal ou imaginário, existe de fato, e o faz em um plano essencialmente diferente dos espaços conhecidos. Ramal (2002) complementa tal noção, afirmando que:

\footnotetext{
Hoje em dia conhecemos um novo espaço de leitura e escrita. As letras - concretas e palpáveis - transformaram-se em bytes digitais; a página em branco é o campo do monitor; a caneta é o teclado. Há, agora, uma estranha separação entre o nosso corpo (real) e o texto (virtual). Até que seja impresso (atualizado), o texto pode ficar indefinidamente nessa virtualidade. É um novo modo de lidar com a escrita, característico de um momento que alguns denominam pós-moderno e outros cibercultura. (RAMAL, 2002, p. 72).
}

Dessa forma, a comunicação no ciberespaço ocorre de maneira significativa sob o ponto de vista de que os cibernautas interatuam por meio de gêneros discursivos escritos. Desse modo, o ciberdiscurso é construído na medida em que os cibernautas estabelecem relações escritas constantes, mesmo que sejam provisórias, diante do conjunto de polifonias concordantes, em que produzem suas vozes, construindo processos cognitivos que os constituem como seres sociodiscursivos na sociedade em que a cultura está indexada à ação dialógica por meio da escrita. Portanto, o ciberdiscurso é o compartilhamento imediato do ato linguístico discursivo; 


\section{Linguagens - Revista de Letras, Artes e Comunicação - ISSN 1981- 9943 \\ Blumenau, v. 14, n. 2, p. 114-127, maio/ago. 2020. \\ DOI: http://dx.doi.org/10.7867/1981-9943.2020v14n2p114-127}

a linguagem anexada aos usuários, praticada dentro do ciberespaço (internet), ou seja, a prática da escrita na Web.

Nesse caminho, a presente pesquisa visa investigar, por meio da teoria semiótica greimasiana, as formas e mecanismos de manipulação recorrentes nesta mídia de marketing, referente ao produto turístico do estado de Mato Grosso do Sul, mais especificamente a cidade de Bonito. Para justificar o presente estudo, considera-se a importância de não ser indiferente à tecnologia, conforme Kielgast e Hubbard (1997) e, desse modo, buscamos descrever como a incorporação de ferramentas digitais pode fundar outros modos de construção de sentidos na configuração discursiva sobre a temática do turismo. Nosso pressuposto é o de que a análise do arquivo que compõe nosso corpus permitirá buscar nas redes de significações, a compreensão da linguagem verbal, não-verbal e, ainda, determinar os processos de subjetivação que constroem a imagem do turismo em nossa região.

Consideramos que o discurso veiculado pela mídia tanto se comporta como uma prática social repetidora de certa ideologia quanto, direta ou indiretamente, deixa-se atravessar pelas muitas vozes divergentes também constitutivas da história. Compreender melhor como o sentido se constitui na organização enunciativa desses textos pode, ainda, fornecer subsídios para a geração de estudos com vistas à melhoria da qualidade de vida da sociedade no que se refere à expressão cultural, ao descobrimento de possíveis necessidades de intervenção capazes de melhorar os serviços receptivos oferecidos ao turista, à educação e à constituição do conhecimento.

Ademais, importa considerar que, nos últimos tempos, tem crescido o interesse pelos estudos semióticos da narrativa, sendo cada vez mais recorrente a busca e a produção de análises de textos verbais e até mesmo sincréticos (notícias, propagandas, epístolas e textos midiáticos em geral). A partir disso, vale destacar aqui a pesquisa, dos últimos cinco anos, de Barros (2015) e Teixeira (2020), que tratam, a partir do viés semiótico, da análise de discursos pertencentes ao ciberespaço.

Barros (2015), a partir da análise das categorias de tempo, espaço e pessoa, define os discursos online como complexos, pois "ocupam posição intermediária entre a fala e a escrita" (BARROS, 2015, p. 18-19). Isso se deve, provavelmente, à facilidade de (re)edições da mídia, pois, "tal como na escrita, a formulação e a reformulação não deixam marcas no texto final refeito e, tal como na fala, as diferentes versões, conservadas no texto geral online que as integra, explicitam as correções, paráfrases e repetições do processo de reformulação textual" (BARROS, 2015, p. 20). Dando continuidade aos seus dizeres, Barros analisa ainda a 


\section{Linguagens - Revista de Letras, Artes e Comunicação - ISSN 1981- 9943 \\ Blumenau, v. 14, n. 2, p. 114-127, maio/ago. 2020. \\ DOI: http://dx.doi.org/10.7867/1981-9943.2020v14n2p114-127}

organização enunciativa e veridictória ${ }^{3}$ dos discursos da internet, ou seja, a autora constata que tais discursos podem ser tidos como verdadeiros, parecem e são verdadeiros; como mentiras, que parece mas não são verdadeiros; ou então como segredo, que não parecem mas são verdadeiros.

Já Teixeira (2020), por sua vez, publicou em um Dossiê especial em homenagem à Barros, um artigo com algumas considerações sobre a análise semiótica de discursos provenientes do ciberespaço, lembrando-nos de que a cibercultura é "entendida não apenas como questão tecnológica, mas como forma de vida da sociedade contemporânea" e é "capaz de gerar impactos socioculturais ainda pouco estudados [...]" (TEIXEIRA, 2020, p. 28). Diante de tais discussões, o presente trabalho torna-se peculiar por optar pela utilização do suporte teórico que concerne às tipologias de manipulação previstas pela sintaxe narrativa da semiótica discursiva, abordando, especificamente, a temática do turismo pantaneiro.

Com relação às pesquisas que tomam a temática turismo, como objeto de análise, podemos citar Gomes e Nakatani (2019) e Ramos, Ferreira, Gandama, Lima (2010). Contudo, tais estudos não estão no âmbito da semiótica discursiva de Greimas, pois se apoiam nos pressupostos semióticos de Pierce ${ }^{4}$.

Em relação aos estudos do âmbito da semiótica greimasiana que tomam o discurso online sob a temática turismo como objeto, destacam-se as pesquisas de Mello (2013; 2015), que propõem, mais a fundo, a relação entre semiótica e turismo especificamente. Entretanto, a autora se dedica à análise do texto-fotografia turística mais precisamente. Em nosso caso, buscamos analisar o discurso turístico veiculado por reportagens, consideradas como um texto todo de sentido. Nessa perspectiva, o presente artigo também colabora e amplia a noção de aplicação analítica-metodológica da semiótica discursiva, tendo em vista nosso objetivo de realizar uma análise sobre um objeto pertencente ao ciberespaço, isto é, à internet, e, ainda, relacionado à temática turismo, mais especificamente ao turismo pantaneiro, um dos principais mercados turísticos do Brasil. Além disso, vale ressaltar que diante das atuais discussões sobre fake news, torna imprescindível a aplicação das ferramentas semióticas capazes de identificar os mecanismos de manipulação no discurso online, o que demonstra, nesse ponto, uma das principais contribuições do presente artigo para o campo teórico.

\footnotetext{
3 "Na veridicção, as relações modais entre o ser e o parecer, que determinam os discursos como verdadeiros, mentirosos, secretos ou falsos, e levam seus destinatários a neles acreditar ou não, têm na internet características próprias" (BARROS, 2015, p. 22).

${ }^{4}$ A semiótica de Pierce, ou americana, possui um caráter mais filosófico e tem a noção de signo desprendida da noção linguística saussuriana. A semiótica de Greimas, ou francesa, por sua vez, segue a linhagem de Saussure.
} 


\section{Linguagens - Revista de Letras, Artes e Comunicação - ISSN 1981- 9943 \\ Blumenau, v. 14, n. 2, p. 114-127, maio/ago. 2020. \\ DOI: http://dx.doi.org/10.7867/1981-9943.2020v14n2p114-127}

Assim sucedeu a primeira etapa de nossa metodologia: a seleção do objeto. Após a elaboração de um arquivo com todas as oportunidades de possíveis objetos de análise, incluindo reportagens, propagandas, matérias etc., todas do mundo virtual, foi selecionada a reportagem Bonito: o paraíso brasileiro do ecoturismo no MS, do Portal N10. O site é um canal de notícias do Rio Grande do Norte e foi criado em 2014, a fim de contribuir com a busca de informações locais, regionais e até internacionais.

Para nossa surpresa, encontramos a mesma reportagem, mesmo título e mesmos textos verbais e não-verbais, em outro site, desta vez no O Pantaneiro, portal eletrônico jornalístico sul-mato-grossense. A diferença se mostra por meio da dimensão dos aspectos semióticos dispostos nos sites estudados. A página pantaneira possui um interesse mais relacionado às notícias, entretenimento e afins das cidades ligadas ao Pantanal, enquanto o Portal N10, em esfera ampla, traz informações gerais do Brasil e do mundo. Posteriormente à seleção do objeto de análise, foram realizadas leituras para o embasamento teórico.

\section{SEMIÓTICA DICURSIVA E SEU DESDOBRAMENTO VISUAL}

Vale ressaltar que dentre as variadas perspectivas dos estudos semióticos, aqui não tratamos do viés americano ou russo mas do francês, o da Semiótica Discursiva de Greimas. Como afirma Fiorin, o escopo da semiótica francesa: “é estudar a produção e a interpretação dos discursos [...] Ela vai além da semântica, porque seu objeto não é o plano do conteúdo das línguas naturais, mas o discurso veiculado pelos textos." (FIORIN, 2017, p. 151). Assim, analisamos o discurso turístico veiculado pelo texto-reportagem do Portal N10. Para tanto, utilizamo-nos, a primeira instância, dos pressupostos de Barros (1990) e Fiorin (2011). Foram lidos também trabalhos outros ligados à teoria semiótica, como o livro de Batistote (2012).

Uma das questões mais sofisticadas que a semiótica oferece como ciência é a capacidade de ter desenvolvido seus próprios recursos teóricos-metodológicos de análise. A análise semiótica promove um percurso que gera o(s) sentido(s) de determinado texto, conforme aponta Batistote (2012, p. 34): “A semiótica concebe o texto como um percurso que vai gerando o sentido total do texto, partindo do nível mais abstrato e simples até o nível mais concreto e complexo", ou seja, a leitura semiótica segue um trajeto previsto de análise no qual se gera o sentido. Os níveis são divididos em três: o nível fundamental, o nível narrativo e o nível discursivo.

Tais níveis são propostos pela semiótica como ferramentas de análise, assim o analista tem autonomia em identificar quais operações irá utilizar para análise. O texto evidencia a 


\section{Linguagens - Revista de Letras, Artes e Comunicação - ISSN 1981- 9943 \\ Blumenau, v. 14, n. 2, p. 114-127, maio/ago. 2020. \\ DOI: http://dx.doi.org/10.7867/1981-9943.2020v14n2p114-127}

metodologia. Portanto, para nossa análise, daremos enfoque ao nível narrativo, tendo em vista que, segundo o percurso gerativo, é nas estruturas narrativas que se investiga os processos de manipulações.

No que concerne às questões de manipulação previstas pela perspectiva semiótica, Fiorin (2011,p. 29) afirma que "uma narrativa complexa estrutura-se numa sequência canônica, que compreende quatro fases". Em outras palavras, o processo de manipulação possui quatro fases: manipulação, competência, performance e sanção. Sobre a manipulação em si, Barros afirma existirem "quatro grandes classes de manipulação" (BARROS, 1990, p. 31): por tentação, intimidação, sedução e provocação.

Todas as considerações acima estão no âmbito do plano do conteúdo do texto, plano do percurso que gera o discurso. Entretanto, além do plano do conteúdo, a semiótica vai tratar do plano da expressão, a maneira em que o texto vai manifestar seu conteúdo. Entretanto, existem formas outras de manifestação além da verbal-escrita, e, ainda assim, a semiótica se empenhará a analisá-las. Conforme afirma Fiorin (2017, p. 151): “[...] a semiótica é uma teoria de todos os sistemas de significação, dos discursos manifestados por quaisquer tipos de texto (um texto verbal, uma pintura, um filme, uma ópera, uma publicidade, uma escultura e assim por diante)". Assim, a semiótica analisa não só o texto verbal escrito, mas o da ordem da canção, o visual o fílmico, o escultórico, e assim por diante.

Por isso, desenvolvemos ainda, uma análise complementar com enfoque à semiótica visual, observando os efeitos de sentidos produzidos pelas imagens dispostas na reportagem de ambos os sites comentados (Figuras 2 e 3). Consideramos a reportagem como um todo de sentido, incluindo sua composição imagética. Para tanto, apoiamo-nos em Pietroforte (2007), relevante estudioso da semiótica visual no Brasil.

A análise do desdobramento visual da semiótica discursiva prevê algumas categorias que necessariamente são correlacionadas à análise do conteúdo. As categorias pontuadas por Pietroforte (2007) são: (A) Categoria eidética: em questão a relação das formas; (B) Categoria cromática: em questão a relação das cores; (C) Categoria topográfica: determinante à disposição das cores e formas.

Por fim, vale ressaltar que a semiótica visual não é isolada da semiótica greimasiana, conforme afirma Pietroforte (2007, p. 11): “[...] desde que definam a significação como objeto de estudo e o façam de acordo com o percurso gerativo do sentido, trata-se do desenvolvimento do ponto de vista proposto por Greimas". Assim, nosso objetivo também é analisar visualmente os textos imagéticos da página a fim de evidenciar até que ponto tais manifestações somam para 


\section{Linguagens - Revista de Letras, Artes e Comunicação - ISSN 1981- 9943 \\ Blumenau, v. 14, n. 2, p. 114-127, maio/ago. 2020. \\ DOI: http://dx.doi.org/10.7867/1981-9943.2020v14n2p114-127}

o efeito manipulador previsto pela análise do plano do conteúdo. A relação entre plano do conteúdo com o plano da expressão emerge ao semissimbolismo.

A partir disso, comparamos, paralelamente, o plano de expressão dos dois sites da reportagem-corpus, a fim de evidenciar como os efeitos de sentidos visuais de um site, com imagens dispostas de forma distinta do outro, podem contribuir em diferentes medidas à manipulação. Nesse sentido, verificamos a configuração do texto verbal e visual e seus recursos persuasivos como um todo de sentido.

\section{MANIPULAÇÃO NO DISCURSO ONLINE}

$\mathrm{Na}$ manipulação, o destinador [...] exerce a persuasão para convencer o destinatário a aceitá-lo. (BARROS, 1990, p. 31)

Concluindo tais contextualizações teóricas, pontuamos as presentes questões, ligadas agora, ao corpus Bonito: o paraíso brasileiro do ecoturismo no MS. Escrita por Romário Nicácio, redator e co-fundador do portal (N10), veículo da reportagem sobre Bonito se mostra como a maioria de sua tipologia, possui um discurso frequentemente atrativo acerca de seu produto, neste caso, a cidade turística de Bonito.

A partir das principais maneiras de persuasão previstas por Barros (1990, p. 31), evidenciamos dois tipos de manipulação mais recorrentes no discurso do objeto. Primeiro, predominantemente, por tentação. Tal manipulação pode ser evidenciada no texto em momentos como: "Gosta de aventura? Então não deixe de fazer o rapel do Abismo Anhumas, que vai levar você para dentro da caverna por 72 metros.” (NICÁCIO, 2017).

Idêntica situação, Barros (1990) aponta no contexto de uma mãe tentando convencer o filho a comer, dizendo que se ele comer ganhará uma recompensa. Ocorre uma manipulação por tentação similar, pois, segundo o narrador, caso a pessoa vá a Bonito, ganhará sua recompensa, poderá desfrutar do rapel no Abismo Anhumas, que irá levá-lo para uma caverna etc., e caso ele recuse Bonito, estará perdendo essas e muitas outras oportunidades descritas ao longo do texto. Assim, o destinador manipulador tenta causar sob o enunciatário uma sensação de poder/dever-fazer o que se propõe.

Além da manipulação por tentação, na reportagem também há indícios de manipulação por sedução. A sedução ocorre quando o destinador manifesta um juízo positivo à competência do manipulado, ou seja, tenta convencê-lo de que possui capacidade para realizar tal ação, como por exemplo: "Se você quiser conforto, pode optar por hotéis de luxo, pousadas e pelos resorts; se quiser uma viagem econômica, também há albergues e hotéis econômicos" (NICÁCIO, 


\section{Linguagens - Revista de Letras, Artes e Comunicação - ISSN 1981- 9943 \\ Blumenau, v. 14, n. 2, p. 114-127, maio/ago. 2020. \\ DOI: http://dx.doi.org/10.7867/1981-9943.2020v14n2p114-127}

2017). Dessa forma, tal fragmento se constitui de um processo duplo de manipulação, tanto por tentação quanto por sedução. A tentação, novamente, acontece prometendo uma recompensa, nesse caso, a promessa de encontrar hotéis baratos e obter uma viagem econômica. Já por sedução, acontece que, o destinatário, leitor-turista, poderia pensar em não ter condições de viajar e se hospedar em Bonito, mas é nesse momento que o manipulador mostra que a cidade tem outras opções e todos têm a possibilidade de reservar uma hospedagem confortável, o leitor tem condições de adquirir o presente produto.

Cabe, aqui, destacar o conceito de hipertexto. Segundo Koch (2005, p. 63) "o hipertexto constitui um suporte linguístico-semiótico hoje intensamente utilizado para estabelecer interações virtuais desterritorializadas". Assim, um texto só é hipertexto se contiver nele ligações que possam acessar outros sites, textos ou quaisquer outras informações que contribuam para a informação do texto bruto inicial. Essas possibilidades de informações outras complementares, geralmente, são acessadas por meio de links e podem ocorrer tanto no ambiente virtual quanto no manuscrito/manual. O primeiro acontece por meio de (hiper)links que são postos no corpo do texto que, quando clicados, encaminham para páginas outras. Já o segundo, o manual, considera-se hipertexto quando possui notas de rodapé e afins que são consideradas as chamadas informações complementares comentadas anteriormente.

Nessa perspectiva, nosso objeto é considerado hipertexto e podemos pontuar alguns fatores $(\mathrm{KOCH}, 2005)$ que contribuem ou fazem parte de seu funcionamento, tais como: (a) está no ambiente virtual; (b) há links para o leitor compartilhar a reportagem em suas redes sociais; (c) as propagandas que concorrem a atenção são todas clicáveis e encaminham para seus possíveis fornecedores e; (d) no corpo do texto, no último parágrafo, há a palavra “passagens” que por sua vez é clicável e associada a um link.

O dado (d) possibilita maior exploração, pois, é nesse ponto, que o nosso objeto como um hipertexto, soma ao potencial de manipulação da reportagem. O fato de existir esse link sobre a palavra 'passagens' reforça o discurso persuasivo contido no texto verbal da reportagem. $\mathrm{O}$ autor mostra todos os porquês e todas as vantagens para ir à cidade de Bonito, e direciona a forma de se realizar isso, pontuando um hiperlink. O hiperlink, sobre a palavra 'passagens', inserida no corpo do texto, encaminha o leitor diretamente para o site ViajaNet.com.br, página de venda de passagens da companhia aérea Latam, anteriormente TAM. Portanto, na intenção de se efetuar a compra o mais rápido possível, os fatores de hipertexto postos sobre o corpus podem conduzir o sujeito leitor a, pelo menos, conhecer a ideia de como poderia adquirir ou conhecer o caminho de ida para usufruir do produto "paraíso 


\section{Linguagens - Revista de Letras, Artes e Comunicação - ISSN 1981- 9943 \\ Blumenau, v. 14, n. 2, p. 114-127, maio/ago. 2020. \\ DOI: http://dx.doi.org/10.7867/1981-9943.2020v14n2p114-127}

brasileiro". Outra constatação é que a palavra passagens até então clicável na reportagem do Portal N10, não é clicável na versão de O Pantaneiro.

Refletindo ainda sobre o poder de persuasão do corpus, observamos que a presença do texto não-verbal, pode também estar ligado e/ou contribuindo para o processo de manipulação. Vejamos a imagem recortada:

Figura 1. Imagem capa da reportagem Bonito: o paraíso brasileiro do ecoturismo no MS

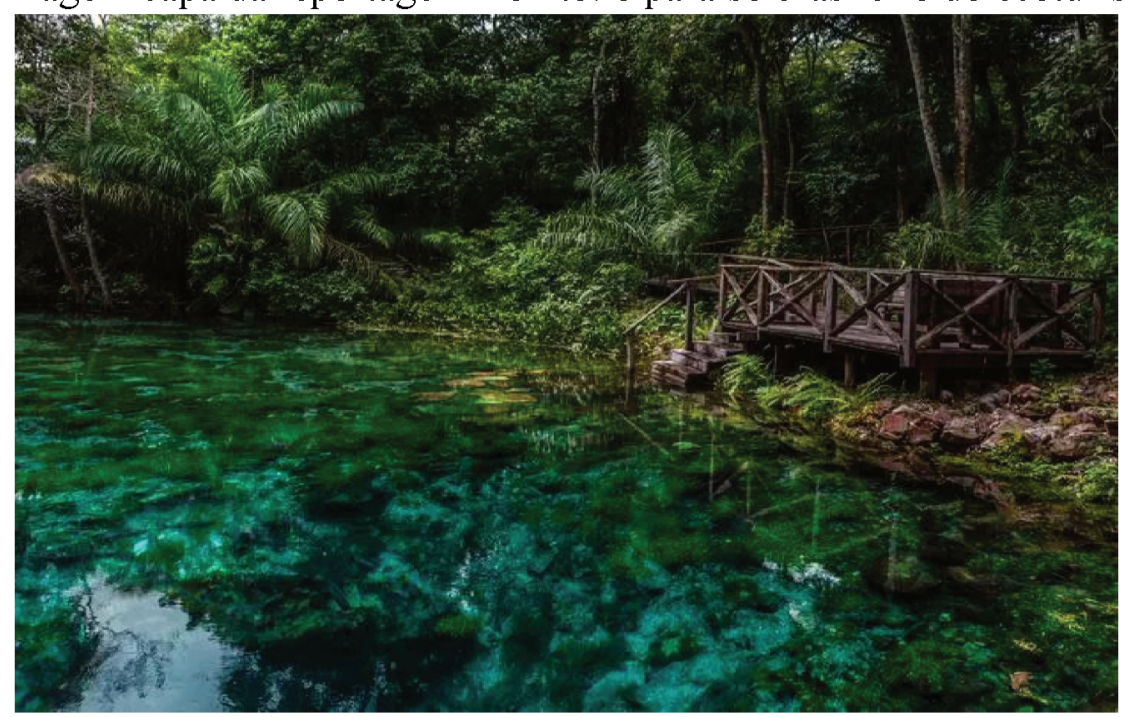

Fonte: https://oportaln10.com.br/bonito-o-paraiso-brasileiro-de-ecoturismo-no-ms-63584/

Analisando a configuração do texto visual para a produção de sentido total do nosso objeto, chegamos a algumas conclusões. Posterior ao título, "Bonito: o paraíso brasileiro do ecoturismo no MS", a imagem principal (Figura 1) é posta como representação do "paraíso brasileiro". Dessa forma, quando se diz "paraíso brasileiro" imagina-se, em primeira instância, a imagem de um lugar, dito brasileiro, que seja figuratizada por um elemento ligado ou próximo ao divino, inalcançável. Nossa imagem principal é predominantemente escura com a presença significativa de sombra, ou seja, está longe do estágio de deslumbramento.

Sobre o deslumbramento, Greimas (2012, p. 26) afirma que "a luz é o patamar mais profundo da visualidade", ou seja, sem luz, sem visualidade, uma imagem melhor selecionada, mais iluminada, poderia proporcionar efeitos de relação com o "paraíso brasileiro" mais coerentes e atrativas. Ademais, depois da leitura do título da reportagem, a imagem capa reflete ao não comprazimento da promessa "paraíso" do sujeito leitor, em outras palavras, há uma ruptura de expectativa que não contribui de forma esperada ao poder de persuasão do corpus como um todo. 


\section{Linguagens - Revista de Letras, Artes e Comunicação - ISSN 1981- 9943 \\ Blumenau, v. 14, n. 2, p. 114-127, maio/ago. 2020. \\ DOI: http://dx.doi.org/10.7867/1981-9943.2020v14n2p114-127}

Entretanto, ainda que a imagem, a sua maneira, não contribua tanto com o efeito manipulativo do texto verbal, acreditamos que o destinador, por sua vez, desenvolve sua competência na realização da performance. Todavia, tal competência não é explícita no texto. A partir disso, nesses casos, Fiorin (2011, p. 32) afirma que "muitas fases ficam ocultas e devem ser recuperadas a partir das relações de pressuposições", ou seja, em casos como o do texto analisado, de sua sequência canônica não estar por inteira evidente, deve-se buscar sua completude por meio do campo das pressuposições. Por isso, pressupomos que a performance de manipulação é bem sucedida. De fato, seu caminho até a sanção se conclui, tendo em vista que a cada temporada que passa, Bonito ainda se mantém firmemente representada em potencial (eco) turístico no Brasil.

Como resposta às nossas pressuposições, investigamos, estatisticamente, o empenho do turismo de Bonito. E, dentre outros fatores mais concretos, os dados confirmam a sanção positiva da cidade turística em questão.

Figura 2. Estatísticas de total de passeios visitados em Bonito anual comparando os anos de 2015 a 2018

OBSERVATÓRIO DO TURISMO E EVENTOS DE BONITO-MS | DEZEMBRO 2018

3. DESEMPENHO DOS ATRATIVOS TURÍSTICOS

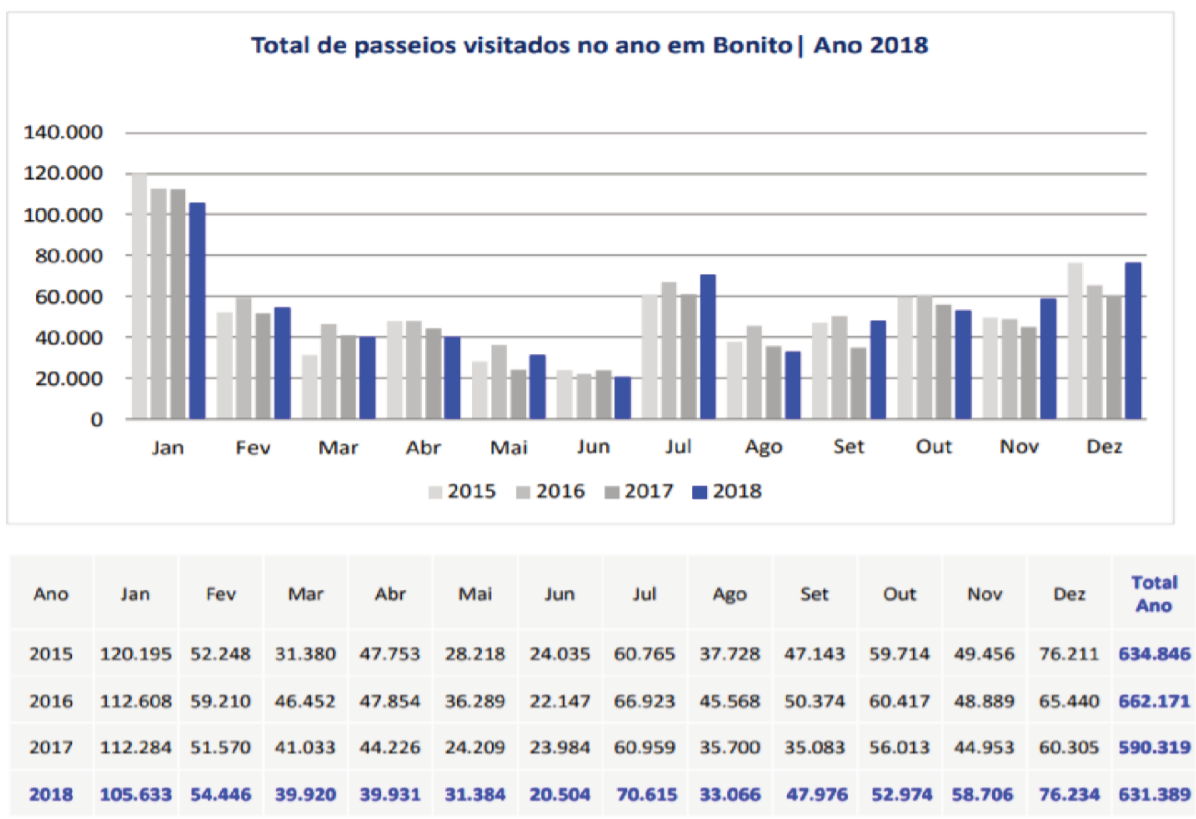

Fonte: http://otbonito.com.br/wp-content/uploads/2019/06/OTEB-Boletim-2018_12.pdf

As presentes informações da OTEB - Observatório do Turismo e Eventos de Bonito MS afirmam que a cidade em foco possui forte potencial turístico, mantendo entre os anos de 2015-2018 uma média, por exemplo, de 629.681 visitas anuais nos passeios oferecidos pela 


\section{Linguagens - Revista de Letras, Artes e Comunicação - ISSN 1981- 9943 \\ Blumenau, v. 14, n. 2, p. 114-127, maio/ago. 2020. \\ DOI: http://dx.doi.org/10.7867/1981-9943.2020v14n2p114-127}

cidade. A partir dos presentes dados, pressupomos que evidenciam certa confirmação de que a manipulação feita pela mídia de modo geral, que aborda a temática do turismo de Bonito, possivelmente, promoveu sua competência, já que a sanção é eufórica do ponto de vista do destinador manipulador, e, além dele, das instituições privadas, a prefeitura e o social bonitense que, ainda não obtendo seus devidos papéis narrativos, também se beneficiam dos efeitos de divulgação e de manipulação do marketing em questão.

Além da questão plástica tratada anteriormente acerca da fotografia-capa da reportagem em questão, observamos que a reportagem ainda que publicada em portais diferentes, poderia até ser idêntica em texto verbal, mas no que diz respeito às questões de textos não verbais, não idênticos entre os portais, emitem efeitos de sentidos, até certo ponto, divergentes no plano da expressão, tratados a partir de agora.

Como postula Pietroforte (2007), o plano da expressão é dividido em algumas categorias que auxiliam no entendimento dos efeitos de sentidos emitidos por um objeto plástico ou visual, são elas: eidética, cromática e topológica.

A categoria eidética, que tem seu olhar voltado à forma do objeto, faz-nos perceber que a imagem de uma paisagem da cidade Bonito (MS) é posta como destaque, obtendo a atenção principal na capa da reportagem. Vejamos pela página de rosto do Portal N10 (Figura 3):

Figura 3. Reportagem Bonito: o paraíso brasileiro do ecoturismo no MS

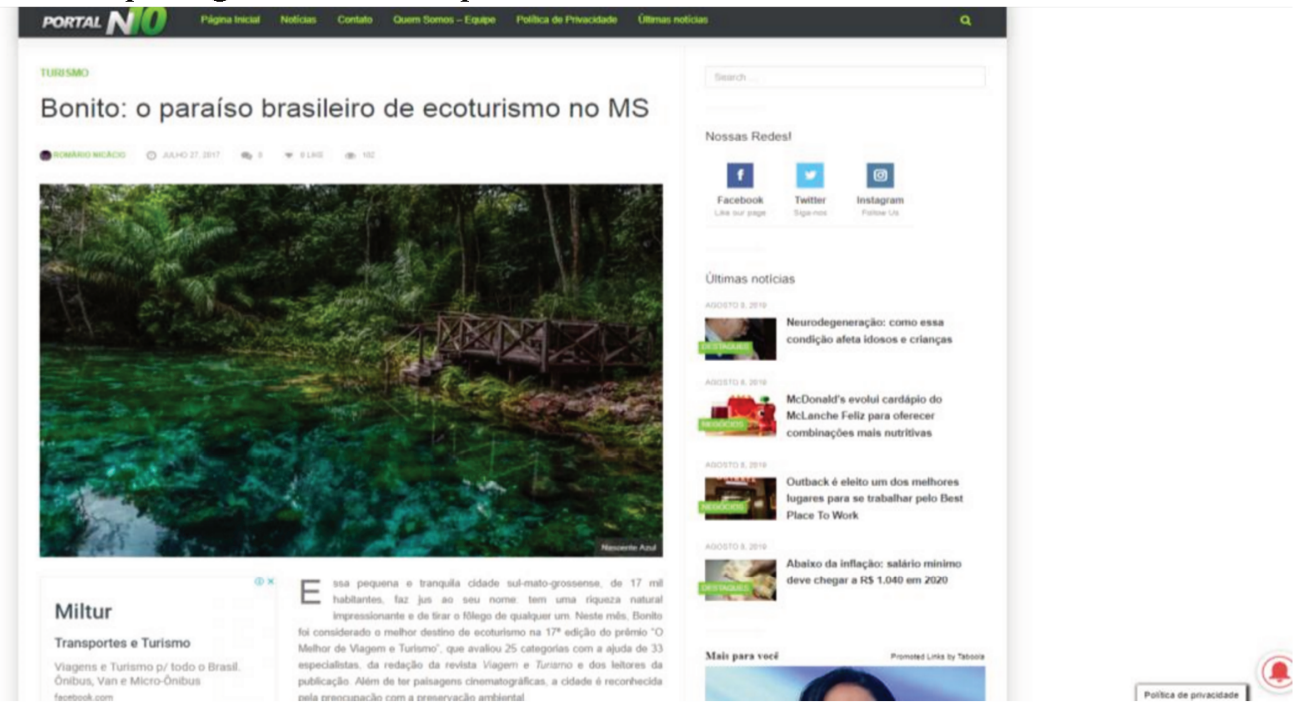

Fonte: https://oportaln10.com.br/bonito-o-paraiso-brasileiro-de-ecoturismo-no-ms-63584/

Diferentemente, no jornal eletrônico O Pantaneiro, a imagem principal é reduzida e sua nova projeção, agora no mesmo formato da propaganda de carne, deixa de lado o poder persuasivo da imagem. Observe no layout do site sul-mato-grossense (Figura 4): 


\section{Linguagens - Revista de Letras, Artes e Comunicação - ISSN 1981- 9943 \\ Blumenau, v. 14, n. 2, p. 114-127, maio/ago. 2020. \\ DOI: http://dx.doi.org/10.7867/1981-9943.2020v14n2p114-127}

Figura 4. Reportagem repost Bonito: o paraíso brasileiro do ecoturismo no MS, desta vez no site O Pantaneiro

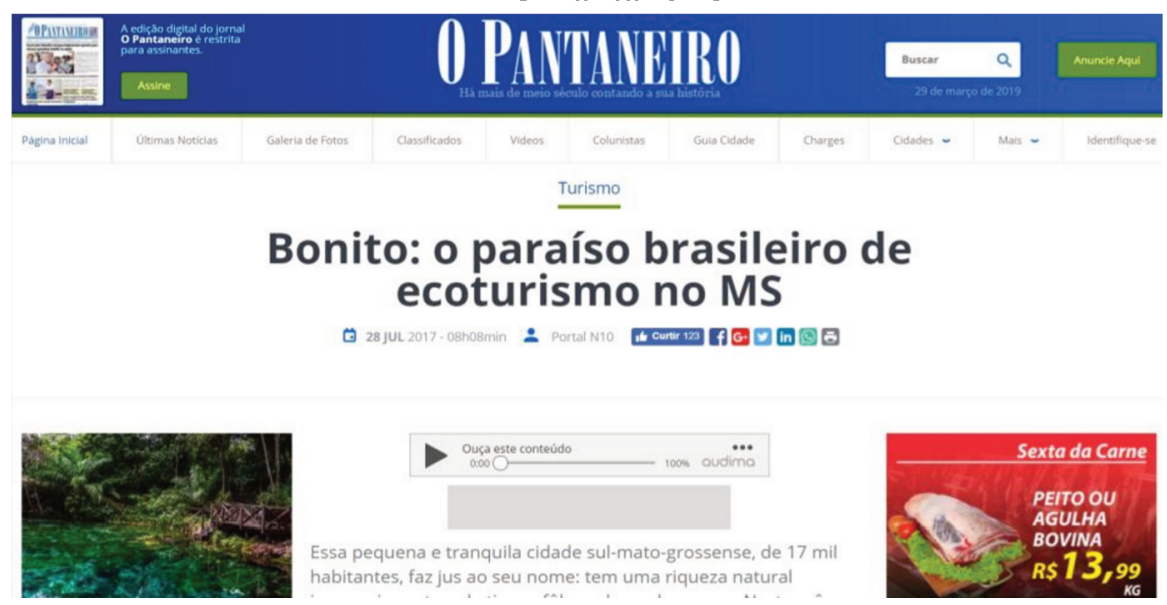

Fonte: http://Www.opantaneiro.com.br/turismo/bonito-o-paraiso-brasileiro-de-ecoturismo-noms/132459/

$\mathrm{Na}$ categoria cromática, percebemos harmonização entre as cores do layout do site (Figura 3) e a imagem principal, fazendo com que a capa permaneça, ainda, em um âmbito de maior atenção e valor. Contrariamente, na página pantaneira (Figura 4), percebemos que os fatores eidéticos ligados aos cromáticos resultam na desvalorização da imagem capa, pois, ainda que haja harmonização entre as cores do layout e da imagem principal, predominantemente de cores frias (azul e verde), a atração da imagem capa não produz o mesmo efeito de sentido ao leitor como no N10, pois, nesse as propagandas de cores quentes dividem a atenção.

A última categoria plástica, a topológica, trata das questões de posição, por isso, aponta que no portal nordestino, a imagem que está em absoluto destaque encontrando-se centralizada, logo após o título "paraíso brasileiro"; enquanto no sul-mato-grossense, a imagem além de reduzida é posicionada ao lado inferior esquerdo, reforçando a ideia de que sua equivalência de valor também é inferiorizada. Portanto, o site O Pantaneiro se mostra recluso ao poder persuasivo no que se diz ao formato, à distribuição de cores e à posição da linguagem nãoverbal. Por outro lado, seu texto verbal se faz competente tanto quanto o texto do Portal N10.

\section{CONSIDERAÇÕES FINAIS}

[...] todo discurso procura persuadir seu destinatário (BARROS, 1990, p. 55)

Em busca de descrever e interpretar, por meio da teoria semiótica greimasiana, as formas e mecanismos de manipulação recorrentes no ciberespaço referentes ao produto turístico do estado de Mato Grosso do Sul, mais especificamente a cidade de Bonito, percebemos que no plano do conteúdo, do percurso gerativo do sentido, na sintaxe narrativa, há duas formas de 
manipulação evidenciadas no corpus Bonito: o paraíso brasileiro do ecoturismo no MS, sendo elas: por tentação (predominantemente) e por sedução. Além disso, foi realizada uma análise comparatista da reportagem entre sua "versão" nos sites Portal N10 e O Pantaneiro, trazendo reflexões e relações analíticas entre o texto verbal, no plano de conteúdo, com os textos não-verbais, ditos visuais, que, pela expressão, combinam-se e colaboram, até certo ponto, com o efeito e capacidade de manipulação da reportagem.

Para produzir um efeito de fim, destacam-se as percepções sociais ligadas à questão turismo, quando a reportagem de fora do estado utiliza expressões em seu favor, de modo a valorizar produto/serviço turístico em Bonito, enquanto a matéria do site sul-mato-grossense $\mathrm{O}$ Pantaneiro, não, possuindo o potencial manipulador apenas em seu texto verbal. Caberia, ainda, interrogar: em que medida esses processos de manipulação estão sendo utilizados e estão obtendo sucesso sobre o sujeito leitor-turista? Essa e outras questões impulsionarão a continuidade de estudos desta natureza, pois foi possível, também, observar recorrências variáveis e, com isso, a possibilidade, inclusive, de a criação de novas perspectivas de prevenção do social em relação à mídia que, hodiernamente, mostra-se corrompida às chamadas fake news, evitando a iminência de conteúdo contaminado no consciente da sociedade e das vias web.

\section{REFERÊNCIAS}

BARROS, Diana Luz Pessoa de. A complexidade discursiva na internet. CASA: Cadernos de Semiótica Aplicada, v.13, n.2, p. 13-31, 2015.

BARROS, Diana Luz Pessoa de. Teoria semiótica do texto. São Paulo: Ática, 1990.

BATISTOTE, M. L F. Semiótica francesa: busca de sentido em narrativas míticas. Campo Grande: Ed. UFMS, 2012.

FIORIN, José Luiz. Elementos de análise do discurso. 15.ed. São Paulo: Contexto, 2011.

FIORIN, José Luiz. Semiótica tensiva. In: Novos caminhos da linguística. São Paulo: Contexto, 2017, p. 151-169.

GIDDENS, A.; PIERSON, C. Conversas com Anthony Giddens: o sentido da modernidade. Rio de Janeiro, FGV. 2000.

GREIMAS, A. J. Da imperfeição. Pref. e trad. de Ana Claudia de Oliveira; apres. de Paolo Fabbri, Raúl Dorra, Eric Landowski. São Paulo: Hacker, 2002.

GREIMAS, A. J.; COURTÉS, J. Dicionário de Semiótica. São Paulo: Contexto, 2008. Título original: Sémiotique, dictionnaire raisonné de la théorie du langage. Vários tradutores. 
KIELGAST, S.; HUBBARD, B. A. Valor agregado à informação: da teoria à prática. Ciência da informação, v. 26, n. 3, 1997. DOI: 10.18225/ci.inf.v26i3.768. Acesso em: 19 dez. 2019.

KOCH, Ingedore Grunfeld Villaça. Desvendando os segredos do texto. 4.ed. São Paulo: Cortez, 2005.

LEMOS GOMES, E.; MASSUKADO NAKATANI, M. S. A Semiótica como metodologia de pesquisa para a análise da comunicação no turismo: estudo da Marca Turística

España. Marketing \& Tourism Review, [S. l.], v. 4, n. 1, 2019. DOI:

10.29149/mtr.v4i1.5040. Disponível em:

https://revistas.face.ufmg.br/index.php/mtr/article/view/5040. Acesso em: 27 jul. 2020.

MELLO, Cynthia Menezes. O modelo semiótico de análise e leitura sensorial de fotografias turísticas. Revista Hospitalidade. São Paulo, v. XII, n. 1, p. 488 - 514, jun. 2015.

NICÁCIO, Romário. Bonito: o paraíso brasileiro de ecoturismo no MS. Portal N10, Natal, 27 jul. 2017. Disponível em: https://oportaln10.com.br/bonito-o-paraiso-brasileiro-deecoturismo-noms-63584/\#ixzz5wXRqEiCJ. Acesso em: 22 nov. 2019.

OBSERVATÓRIO DO TURISMO E EVENTOS DE BONITO-MS. Anuário estatístico do Turismo de Bonito - MS, Bonito, 2018. Disponível em:

http://otbonito.com.br/wpcontent/uploads/2019/06/OTEB-Boletim-2018_12.pdf. Acesso em: 25 jul. 2019.

ORGANIZAÇÃO MUNDIAL DE TURISMO. Turismo internacional: uma perspectiva global. 2. ed. 1997.

PIETROFORTE, A.V. Análise do texto visual: a construção da imagem. São Paulo: Contexto, 2007.

RAMAL, Andrea Cecília. Educação na cibercultura: hipertextualidade, leitura, escrita e aprendizagem. Porto Alegre: Artmed, 2002.

RAMOS, S; FERREIRA, R. V.; GANDARA, J.; LIMA, J. A semiótica utilizada no marketing turístico na cidade de Curitiba - PR - Brasil. Revista Turismo \&

Desenvolvimento, vol. 1, n. 13/14, 2010.

SÁ, R. B. V. de. A imagem do brasil no turismo: construção desafios e vantagem competitiva. São Paulo: Aleph, 2002.

TEIXEIRA, Lucia. Contribuições da semiótica para a análise dos discursos na internet. Entrepalavras, Fortaleza, v. 10, n. esp., p. 27-39, mai. 2020. DOI: 10.22168/2237-63217 esp1801. 